\title{
COLLECTION, GROSS CHARACTERISTICS AND FREEZING OF BABOON SEMEN
}

\author{
D. C. KRAEMER AND N. C. VERA GRUZ \\ Department of Reproductive Physiology, Clinical Sciences Division, \\ Southwest Foundation for Research and Education, San Antonio, Texas 78228
}

(Received 13th May 1969)

This report deals with some gross characteristics of baboon (Papio sp.) semen ejaculated spontaneously or collected by electro-ejaculation. Details of the equipment used and the collection procedure are described and the results of freezing trials are presented. The animals were sedated with Sernylan (Parke, Davis and Co.) at a dose of $0.8 \mathrm{mg} / \mathrm{kg}$ intramuscularly. They were then tied in an extended position while lying on their side on the collection table. The penis was cleaned with a mild detergent and then washed thoroughly with water. It was during this process that one of the males ejaculated on three occasions. These ejaculates are referred to as spontaneous ejaculates.

The stimulator used was a trans-jector (Nicholson, Inc.) in which the voltage output was controlled by a regulator switch with Steps 1 to 7 , with each step having a maximum voltage output of $2 \cdot 4,3 \cdot 2,4 \cdot 5,7 \cdot 5,9 \cdot 5,10 \cdot 5$ and 13.5 volts, respectively, and a cycle frequency of $60 / \mathrm{sec}$. The rectal probe used was designed and built in our laboratory and is $1 \frac{3}{16} \mathrm{in}$. in diameter and $10 \frac{1}{4} \mathrm{in}$. long, with twelve circular copper electrodes ( $\frac{3}{16}$ in. wide) placed $\frac{3}{16}$ in. apart and the first ring (Ring 1) located $1 \frac{3}{16}$ in. from the tip of the probe. By means of an electrode selector switch, any combination of two electrodes could be used at one time. Consistently better results were obtained using Rings 7 and 10 with the probe placed 6 to 7 in. into the rectum. When Rings 1 to 3 were used in combination with other rings, the ejaculates were usually contaminated with urine.

Ejaculation was achieved by gradually increasing the voltage from zero to the maximum output at each step and holding the output at maximum for $5 \mathrm{sec}$ before gradually lowering the voltage back to zero. This procedure was repeated at each step setting for the following duration: Steps 1 and 2, $2 \mathrm{~min}$ each; Steps 3 to 6, 1 min each, and Step 7, 2 min. Ejaculation occasionally occurred at Step 6, but generally semen emission took place at Step 7 (13.5 volts). At times, stripping of the penis was required to clear the urethra of strings of coagulated seminal material. The semen was directed into $15 \mathrm{ml}$ graduated collection tubes from which the fluid and total volume were directly assessed. The volume of the coagulum fraction was determined by measuring its fluid displacement.

Baboon semen, like that of other non-human primates (Hoskins \& Patterson, 1967; Roussel \& Austin, 1967a, 1968) consists of a fluid and a coagulum fraction. The coagulum fraction was separated from the fluid fraction and washed with 


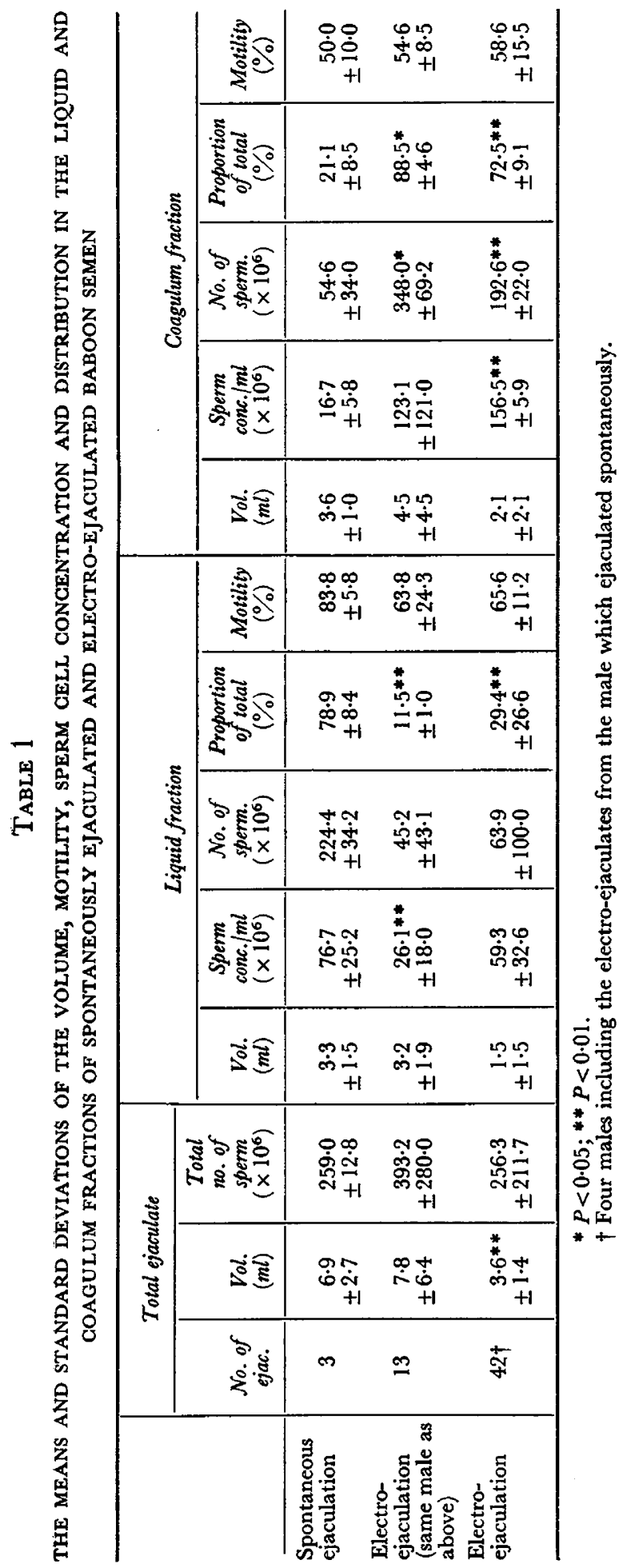


$3 \%$ sodium glutamate solution and then treated with an equal volume of trypsin solution (1\% trypsin in $3 \%$ sodium glutamate) for 30 min at $27^{\circ} \mathrm{C}$ (Roussel \& Austin, 1967a). The percentage of progressively motile spermatozoa was assessed by microscopic examination and sperm concentration was measured by means of a haemocytometer. The volume, motility, sperm concentration and sperm number in the fluid and coagulum fraction of forty-five ejaculates from four males are summarized in Table 1 . The means of the two samples of electroejaculated semen (same male; four males) were compared individually with the means of the spontaneously ejaculated sample and the differences were tested by using a Student's $t$-test (Steele \& Torrie, 1960).

Spontaneously ejaculated baboon semen, which probably closely approximates to semen ejaculated during coitus, consists, like electro-ejaculated semen, of a fluid and a coagulum fraction. The total number of spermatozoa is approximately the same in both types of ejaculate and agrees well with those obtained by Roussel \& Austin (1968) for other non-human primates.

The average total volumes of the two types of ejaculate were not statistically different within the same animal; however, the average semen volume of the

\section{TABLE 2}

THE AVERAGE PRE-FREEZE AND POST-THAW MOTILITY AND SURVIVAL OF SPONTANEOUSLY EJACULATED AND ELECTROEJACULATED BABOON SEMEN FROZEN AND STORED FOR 1 MONTH IN NITROGEN VAPOUR

\begin{tabular}{l|c|cc|c}
\hline \multicolumn{1}{c|}{ Type of ejaculate } & $\begin{array}{c}\text { No. of } \\
\text { trials }\end{array}$ & $\begin{array}{c}|c| \\
\text { Pre-freeze } \\
(\%)\end{array}$ & $\begin{array}{c}\text { Post-thaw } \\
(\%)\end{array}$ & $\begin{array}{c}\text { Survival } \\
(\%)\end{array}$ \\
\hline $\begin{array}{l}\text { Spontaneous ejaculate } \\
\text { Electro-ejaculate }\end{array}$ & 3 & $76 \cdot 7$ & $48 \cdot 3$ & $63 \cdot 1$ \\
\hline
\end{tabular}

animal which ejaculated spontaneously was significantly higher than the average of all samples collected by electro-ejaculation. The sperm distribution in each fraction was markedly different in the two types of ejaculate within the same animal and between animals. The proportion of the total spermatozoa which was in the liquid fraction was significantly higher in the spontaneous ejaculates than in the electro-ejaculates. Conversely, the proportion of the total spermatozoa in the coagulum fraction was significantly lower in the spontaneous ejaculates than in the electro-ejaculates.

Results from freezing trials in nitrogen vapour of both types of ejaculate showed no marked difference in survival rates (Table 2) and are comparable to those obtained by Roussel \& Austin (1967b) with semen of other non-human primates. The semen was diluted so that $1.0 \mathrm{ml}$ of extended semen contained $10 \times 10^{6}$ progressively motile cells using sodium glutamate-egg yolk extender (Roussel \& Austin, 1967b) containing 500 i.u. penicillin and $500 \mu \mathrm{g}$ strepto$\mathrm{mycin} / \mathrm{ml}$ of diluter.

These observations show that electro-ejaculation can be used as a practical method of semen collection in the baboon, as has been shown for other non- 
human primates (Mastroianni \& Manson, 1963; Weisbroth \& Young, 1965; Roussel \& Austin, 1968). However, the relatively higher motility and sperm numbers and the significantly greater portion of spermatozoa obtained in the liquid fraction of spontaneously ejaculated semen suggest the importance of devising other methods by which spontaneous ejaculates may be collected.

The authors would like to thank Mrs Marie A. Rivas and Mr Scott H. Lonis for technical assistance. This work was supported by Public Health Service Research Grant 9-P06-FR-GM00451-04 from the Institute of General Medical Sciences.

\section{REFERENCES}

Hoskins, D. D. \& Patterson, D. L. (1967) Prevention of coagulum formation with recovery of motile spermatozoa from Rhesus monkey semen. F. Reprod. Fert. 13, 337.

Mastroianni, L., JR \& Manson, W. A., JR (1963) Collection of monkey semen by electro-ejaculation. Proc. Soc. exp. Biol. Med. 112, 1025.

Roussel, J. D. \& Austin, C. R. (1967a) Enzymatic liquifaction of primate semen. Int. F. Fert. 12, 288.

Roussel, J. D. \& Austin, C. R. (1967b) Preservation of primate spermatozoa by freezing. F. Reprod. Fert. 13, 333.

Roussez, J. D. \& Austin, C. R. (1968) Improved electro-ejaculation of primates. F. Inst. Anim. Tech. $19,22$.

Steele, R. G. D. \& Torrie, J. H. (1960) Principles and procedures of statistics, p. 73. McGraw-Hill, New York.

Weisbroth, S. \& Young, F. A., JR (1965) The collection of primate semen by electro-ejaculation. Fert. Steril. 16, 229. 